\title{
Memorial address for Motokazu Hori (1929-2013)
}

\author{
Yuji Hiramatsu • Yuzuru Sakakibara
}

Published online: 20 March 2014

(C) The Japanese Association for Thoracic Surgery 2014

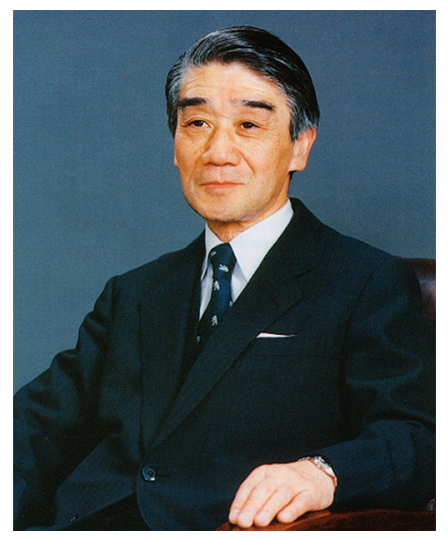

The late Dr. Motokazu Hori, a former Vice President of University of Tsukuba, significantly contributed to the establishment and development of the Department of Cardiothoracic Surgery of the University. At foundation of University of Tsukuba in 1973, Dr. Hori was elected as the first professor of the Department of Cardiothoracic Surgery, Institute of Clinical Medicine, and established the early history of the cardiothoracic department as the chair. Dr. Hori soon started full-fledged cardiovascular and thoracic surgery service and also promoted distinctive programs for related research and medical education.

After graduating from Tokyo University, School of Medicine in 1954, Dr. Hori joined the Kimoto Department of Surgery at Tokyo University and completed his thesis regarding hepatic coma. In 1962, Dr. Hori commenced to study in the Massachusetts General Hospital (MGH),

Y. Hiramatsu $(\square) \cdot$ Y. Sakakibara

1-1-1 Tennodai, Tsukuba, Ibaraki, Japan

e-mail: yuji3@md.tsukuba.ac.jp

Harvard University as a post-doctoral research fellow on the Fulbright scholarship and engaged in the research for hepatorenal syndrome and hepatic encephalopathy in the laboratory of Dr. W. V. McDermott. In MGH, he worked together with Dr. W. Gerald Austin as well as Dr. L. Henry Edmunds, Jr., the present editor of the Annals of Thoracic Surgery. These bonds of friendship lasted long time so that later he sent several young surgeons to Boston and Philadelphia. In 1969, Dr. Hori took up his post as associate professor in the Department of Theoretical Surgery in Tokyo Women's Medical University. Next year, he became professor in the department and served several years until he moved to University of Tsukuba as one of the founding professors of the newly-organized national school of medicine.

Throughout his career in University of Tsukuba, as the professor and chair, Dean of the school of medicine (1988-92), and the vice president (1992-94), Dr. Hori made enormous efforts in the reformation and development of the new-concept of medical education system, so-called Tsukuba style education, as a pioneer in the field. With his continuing endeavor and dedication, University of Tsukuba has been well recognized as a front runner in the innovation of medical education. Despite the hard work as a leader of the department, institute and societies, Dr. Hori paid sincere attention to even every young resident or medical student. He therefore was adored as a mentor by many students, physicians and scientists besides surgeons. Dr. Hori filled various posts such as the president of the Japanese Society of Medical Education as well as the Japanese Society of Artificial Organs successively. He was also a chairperson or council member of many other scientific societies. Dr. Hori was conferred with a decoration and a court rank after he died, and has now truly become a legend of medical education. 
"Noblesse oblige" was his indispensable principle and this spirit in Bushido was underlying his impartiality and calmness. This firm spirit made Dr. Hori dedicate himself to the distinguished professionalism as a surgeon, researcher, teacher and leader. Probably "honorable poverty" was his favorite life style, although he never demanded his students to follow the way. Such a noble ambition and principle, however, will be inevitably succeeded by many of his students and should be certainly inherited to the next generation.

With all his brilliant scientific and educational achievement, Dr. Hori will continue to deserve the admiration of every cardiovascular and thoracic surgeon in this country and even in the world. May his noble soul rest in peace. 